\title{
The Blocking Activity of Different Toxins against Potassium Channels Kv3.4 in RLE Cells
}

\author{
Mehdi Saberi ${ }^{* 1}$ and Edward G. Rowan ${ }^{2}$ \\ ${ }^{1}$ Dept. of Pharmacology and Toxicology, Research Center for Chemical Injuries, Faculty of Medicine, Baghiyatollah \\ University of Medical Sciences, Tehran, Iran; ${ }^{2}$ Dept. of Physiology and Pharmacology, University of Strathclyde, 27 \\ Taylor street, Glasgow, G4 ONR, Scotland, UK
}

Received 17 January 2006; revised 28 May 2006; accepted 3 June 2006

\begin{abstract}
Background: $\mathrm{K}^{+}$channel toxins are essential tools for the first purifications, analysis of subunit structures and brain localization of voltage-gated $\mathrm{K}^{+}(\mathrm{Kv})$ channels. The effects of a lot of toxins on $\mathrm{Kv}$ are not fully known. Methods: Using whole-cell patch clamping technique the action of a series of toxins on Kv3.4 current in rat liver cells with expressed Kv3.4 channels (RLE) cloned cells was investigated. The cells were grown in Williams E medium and after 6-8 days, they were suitable for patch clamping. A family of currents was recorded during voltage-clamp steps to various potentials applied from a holding potential of $-60 \mathrm{mV}$ to $60-80$ $\mathrm{mV}$ in $10 \mathrm{mV}$ increments. Results: Upon depolarization, all channels were opened with a sigmoidal time course, reached to the peak within a few $10^{\text {th }}$ of milliseconds and then slowly inactivated. Bath application of tetraethyl ammonium (TEA) or 3, 4-diaminopyridine (DAP) reduced the current dose dependently and inhibited it completely at $3 \mathrm{mM}$ and $25 \mu \mathrm{M}$ respectively. The Bunodosoma granulifera $(\mathrm{BgK})$ and Heteractis magnifica (HmK) toxins at concentrations up to 30 and $10 \mu \mathrm{M}$ respectively could not completely inhibit the current. On the hand, toxins such as $\beta$-bungarotoxin, corotoxin, novel toxin and dendrotoxins I (DIP) and K (DPK) even in high concentrations (up to $100 \mathrm{mM}$ ) had not any significant effect on Kv3.4 current. Comparison of chemical structures of these effective agents with other reported effective toxins such as blood depressing substances (BDS I and II) show no homology between them, but specially the potency of 3, 4-DAP is comparable with these toxins. Conclusion: These results showed that, the Kv3.4 is more sensitive than other $\mathrm{K}^{+}$channels to 3, 4-DAP. The sensitivity of this channel to the TEA is low (at mM concentration). More investigation is necessary to find more selective and potent inhibitor of Kv3.4 channels. Iran. Biomed. J. 10 (4): 169-174, 2006
\end{abstract}

Keywords: Patch clamping, Voltage-gated $\mathrm{K}^{+}(\mathrm{Kv}) 3.4$ channel, Rat liver cells with expressed Kv3.4 channels (RLE) cells, Tetraethyl ammonium (TEA), 3, 4-Diaminopyridine (DAP)

\section{INTRODUCTION}

$\mathrm{D}$ rugs that affect potassium channels are used in the treatment of hypertension, cardiac arrhythmias, type II diabetes mellitus and male pattern of baldness, and also they are under investigation for new applications in central nervous system (CNS) disease such as Alzheimer [1-4]. These channels are the most numerous and diversified ion channel structures. More than 20 mammalian genes encoding the $\alpha$ subunit of voltage-gated $\mathrm{K}^{+}(\mathrm{Kv})$ channels have now been cloned and expressed. They differ from their gating mechanisms, ion conduction properties and regulation [5]. Although $\mathrm{K}^{+}$channels are structurally similar, they can be separated into four distinct classes based on the degree of amino acid sequence homology with $\alpha$ subunit encoded by the drosophila Shaker (Kv1), Shab (Kv2), Shaw (Kv3) and Shal (Kv4) Loci [1, 5]. The number of subfamilies is expanding with the recent identification of new subfamilies of $\alpha$ subunits, which cannot generate $\mathrm{K}^{+}$ channel activity by themselves, but modulate in a specific way the activity of functional Shab-type $\alpha$ subunits [5]. The Kv3 class of K+ channels (Kv3.13.4) exhibits a high voltage for activation and fast rate of deactivation, making them excellent candidates for repolarizing and generating fast action potential [6]. 
Potassium channel $(\mathrm{Kv})$ toxins have been essential tools for the first purification, analysis of the subunit structures, and brain localization of voltage sensitive $\mathrm{K}^{+}(\mathrm{Kv})$ channels [1, 2, 4, 7-9]. Due to their high affinity and specificity, they have also been very useful in the identification of the pore-forming region of some of the $\mathrm{Kv}$ channels [5, 10].

Dendrotoxins (DTx), $\beta$-bungratoxin and mast cell degranulating peptides (MCD) are potent blockers of Kv1.1, Kv1.2 and Kv1.6 channels [2, 6]. Charybdotoxin (ChTx) potently blocks Kv1.3 and Kv1.6 channels [11]. Many other types of $\mathrm{K}+$ channels such as Kv1.4 and Kv1.5 and many of the Shaw and Shal related Kv channels do not yet have a specific pharmacology despite the recent discovery of new $\mathrm{K}$ channel toxins [2, 12]. The most classic toxins used to block $\mathrm{Kv}$ channels are DTx-I, MCD and ChTx. They potently inhibit delayed rectifier $\mathrm{Kv}$ channels, but not rapidly inactivating $\mathrm{K}+$ currents $\left(\mathrm{I}_{\mathrm{A}}\right.$ currents) generated by Kv1.4, Kv3.3, Kv3.4 and Kv4 channel subfamily [11]. In one study, two 43aminoacid peptides from the sea anemone Anemonia Sulcata, namely blood-depressing substance (BDS) I and II identified as the first specific blockers of the rapidly inactivating Kv3.4 channels that reversibly inhibit Kv3.4 channels [5]. But, the activity of toxins such as 3, 4- diaminopyridine (DAP), Bunodosoma granulifera $(\mathrm{BgK})$ and Heteractis magnifica $(\mathrm{HmK})$ on this channel is not known.

In comparison to whole oocytes, cloned $\mathrm{Kv}$ channels stably expressed in mammalian cell lines and studied by patch clamp method are likely to have biophysical properties more closely resembling those of native channels. These cloned $\mathrm{Kv}$ channels are more sensitive to be blocked by certain pharmacological agents and less potential to interact with lipophilic drugs [2].

Based upon these findings, the aim of this study was to evaluate and compare the effects of several drugs and toxins such as tetraethyl ammonium (TEA), 3, 4-DAP, BgK, HmK, corotoxin, novel toxin, dendrotoxins $\mathrm{K}$ (DPK) and dendrotoxins I (DIP) on cloned Kv3.4 channels in rat liver cells with expressed Kv3.4 channals (RLE) cells.

\section{MATERIALS AND METHODS}

Chemicals and toxins. Hanks' solution, FCS, TEA, 3, 4-DAP, and all other chemicals were purchased from Sigma chemical Co. (Poole, UK). Other materials and media required for cell culture were obtained from Gibco BRL, Life Technologies
(Renfrewshire, U.K.). Pure $\alpha$-dendrotoxin and $\beta$ bungarotoxin were obtained from Amersham (Bucks, UK). HmK, BgK, DPI, DPK and corotoxin were kindly provided by Dr. B. Fathi, Department of Physiology and Pharmacology, Strathclyde University (Scotland).

Cell culture. RLE cells were grown in Williams E medium (Sigma Chemical Co., Poole, UK) supplemented with FCA $(10 \% \mathrm{v} / \mathrm{v})$, glutamax I (Gibco BRL Life Technologies, Renfrew shine, UK)

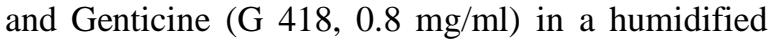
atmosphere of $5 \% \mathrm{CO}_{2} / 95 \%$ air at $30^{\circ} \mathrm{C}$ [13]. Cells were routinely maintained in the laboratory by replanting trypsin-dissociated cells in flacon culture flasks weekly. The cells with the age of 3-6 days were suitable for patch clamping.

Electrophysiological recording and data analysis. The whole cell variant of tight-seal patch clamp technique [14] was used to record potassium channels current in RLE cells.

Voltage clamp was achieved using an EP7 200A amplifier (List Electronic, Darmstadt, Germany). Voltage clamp pulses and data acquisition were controlled by a Viglen 486-DX computer running whole-cell program software [15] interfaced to the EP-7 patch-clamp amplifier via a national Instruments Labmaster PC/PC + board. Cells were maintained at a holding potential of $-60 \mathrm{mV}$ between pulse protocols. Current records in response to voltage steps were filtered at $5 \mathrm{KHz}$. Analogue means were used to cancel capacity transients as far as possible. Series resistance $(\mathrm{RS})$ was $11.2 \pm 1.0$ $\mathrm{M} \Omega(\mathrm{n}=30)$ and up to $80 \%$ compensation for $\mathrm{RS}$ was used. The cells were super fused continuously at a rate of $1-1.5 \mathrm{ml} / \mathrm{min}$ by external solution with composition of (in $\mathrm{mM}$ ): $\mathrm{KCl}, 5 ; \mathrm{NaCl}, 135 ; \mathrm{CaCl}_{2}$, $2 ; \mathrm{MgCl}_{2}, 2$; HEPES, 10, adjusted to $\mathrm{pH}$ of 7.3 at $22^{\circ} \mathrm{C}$. Patch pipettes were pulled from thin walled borosilicate tubing (o.d $1.5 \mathrm{~mm}$; Clarke electromedical Instruments, Pangbourne, Reading, U.K) and fire polished with tip resistance of 5-10 $\mathrm{M} \Omega$ when filled with internal (pipette) solution of the following composition (mM): $\mathrm{KCl}, 140 ; \mathrm{MgCl}_{2}$, 1; HEPES, 10, adjusted to $\mathrm{pH}$ of 7.3 at $22^{\circ} \mathrm{C}$.

Experiments were carried out at room temperature $\left(22-25^{\circ} \mathrm{C}\right)$. In each experiment after recording the whole cell currents at different membrane, potentials (from -60 to $80 \mathrm{mV}$ with $10 \mathrm{mV}$ increment in each stage) were recorded before and after the addition of each toxin. 
(A)
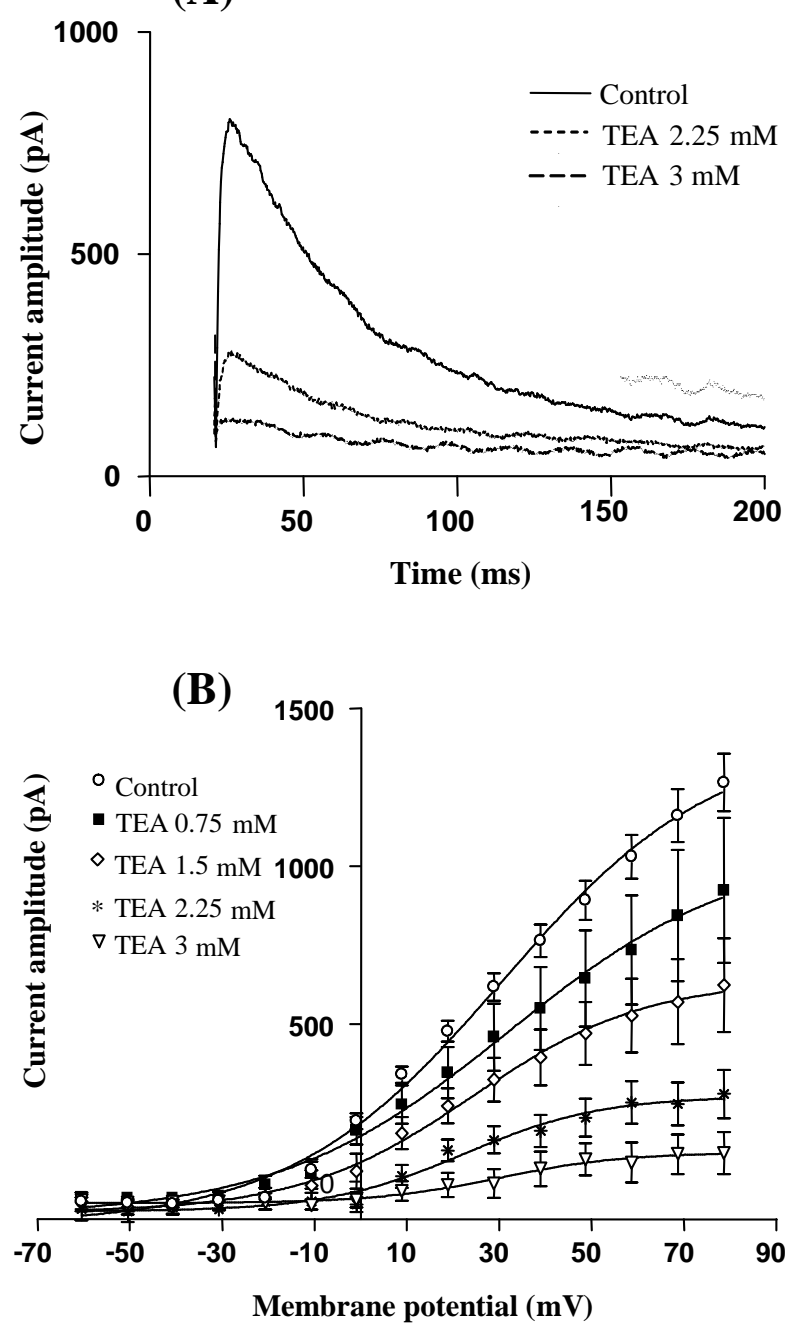

Fig. 1. The effect of tetraethyl ammonium (TEA) on Kv3.4 current in RLE cells. (A) Peak of the current and its change against the time, in control and in the presence of TEA. (B) The $\mathrm{I}-\mathrm{V}$ relationship for the outward $\mathrm{K}+$ current and amplitude of currents at different membrane potentials and different TEA concentrations. The currents were evoked from a holding potential of $-80 \mathrm{mV}$ to a variety of testing potentials. Each point represents the mean. \pm S.E.M of at least 7 experiments.

Statistics. The results are expressed as mean \pm S.E.M. and statistical significance was evauated by one way ANOVA. $P<0.05$ was taken as significant.

\section{RESULTS}

Electrophysiology. The RLE cells were cloned for only Kv3.4 channel. The amplitude of the current could reach to $4000 \mathrm{pA}$ within few ms (Fig. 2A) at $+60 \mathrm{mV}$ with a mean about $1500 \mathrm{pA}$, in comparison to the holding potential at $-60 \mathrm{mV}$ (controls in Figs.
$1 \mathrm{~A}, 2 \mathrm{~A}$ and $3 \mathrm{~A})$.

A family of whole-cell currents recorded from RLE cells containing Kv3.4 channels during voltage-clamp steps to various potentials applied from a holding potential of $-60 \mathrm{mV}$ is shown in Figure 1B for control group (voltage dependency of the current). The outward currents expressed in RLE cells were activated at potentials more positive than $-20 \mathrm{mV}$ from a holding potential negative to $-60 \mathrm{mV}$ (Fig. 1B).

Upon depolarization, all channels were opened with a sigmoidal time course, reached to the peak within few tenth of milliseconds (Figs. 1A, 2A and $3 \mathrm{~A})$.

(A)

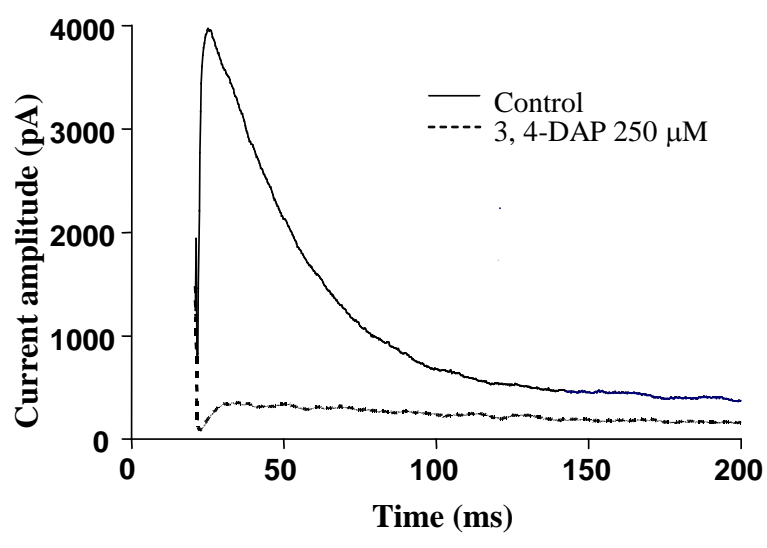

(B)

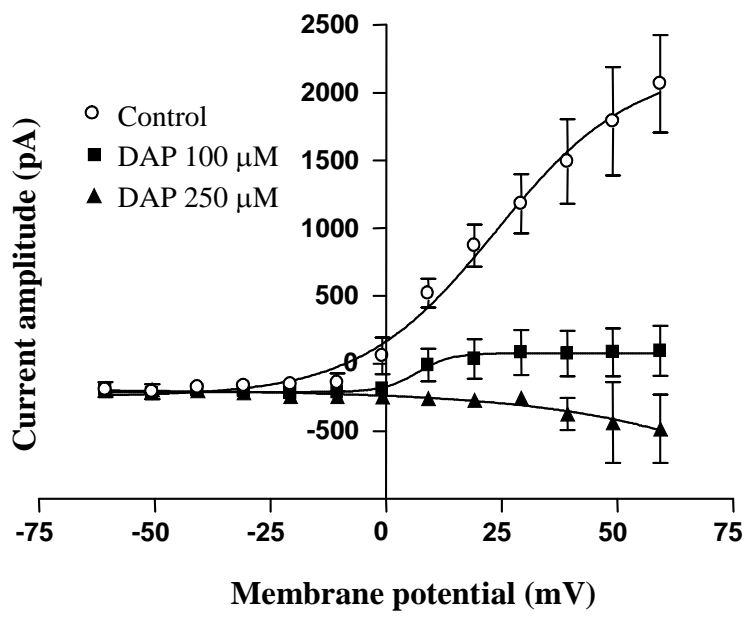

Fig. 2. The effect of 3, 4-Di-aminopyridine (DAP) on Kv3.4 current in RLE cells, (A) Peak of the current and its change against the time, in the control and in the presence of DAP. (B) Effect of different DAP concentrations on outward K+ current. The currents were evoked from a holding potential $-80 \mathrm{mV}$ to a variety of testing potentials. Each point represents the mean \pm S.E.M of at least 7 experiments. 
Pharmacology. The voltage dependence of ion channels was determined at different potentials as is shown in Figs. 1B, 2B, 3B and 4 for controls and different concentrations of TEA, 3, 4-DAP, BgK and HmK respectively at different membrane potentials. TEA reduced the amplitude of current dose dependently $(0.75-3 \mathrm{mM})$ and inhibited the Kv3.4 channels current completely at $3 \mathrm{mM}(P<0.001$, Fig. 1). Also, 3, 4-DAP inhibited completely the current at concentration of $25 \mu \mathrm{M}$ (Fig. 2).

Application of different concentrations of $\mathrm{BgK}$ (5$30 \mu \mathrm{M}$ ) could reduce the amplitude of the current dose dependently, and at concentration of $30 \mu \mathrm{M}$ the

\section{(A)}

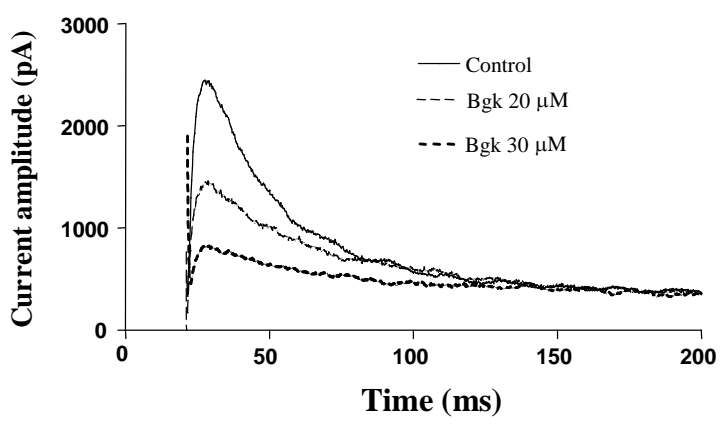

(B)

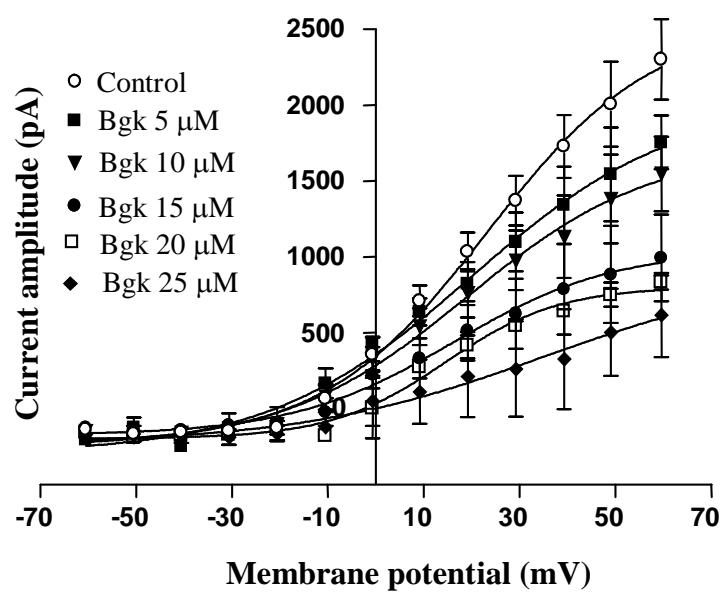

Fig. 3. The effect of Bunodosoma granulifera (BgK) on Kv3.4 current in RLE cells. (A) The time course of the effect of $\mathrm{BgK}$ on current amplitude during patch clamping. The current has reduced significantly at $30 \mu \mathrm{M}$. (B) The effect of different concentrations of $\mathrm{BgK}(5-30 \mu \mathrm{M})$ on the current amplitude of Kv3.4 in RLE cells during voltage step clamping. The currents were evoked from a holding potential of $-80 \mathrm{mV}$ to a variety of testing potentials. Each point represents the mean \pm S.E.M of at least 7 experiments.

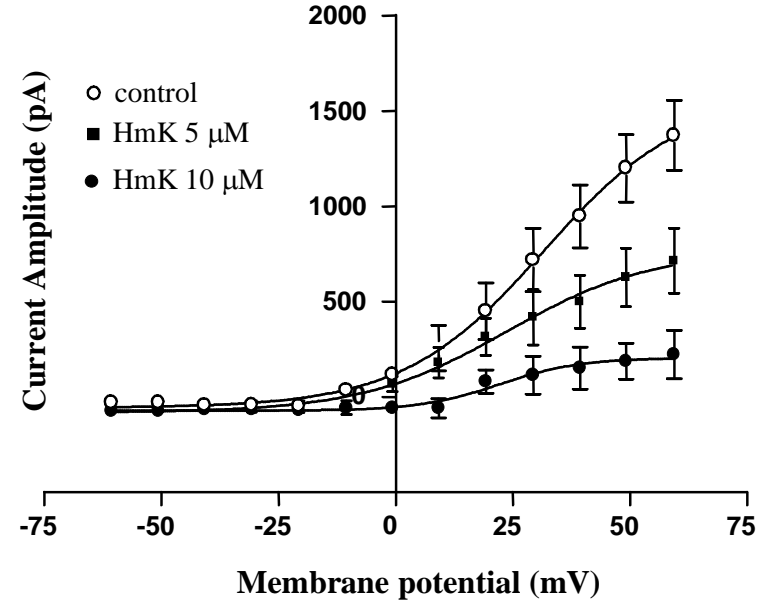

Fig. 4. The I-V relationship for the outward $\mathrm{K}+$ current and the partial inhibitory effect of HmK (Heteractis magnifica) on the current of Kv3.4 channels of RLE cells during voltage clamping. The currents were evoked from a holding potential of $-80 \mathrm{mV}$ to a variety of testing potentials. Each point represents the mean \pm S.E.M of at least 5 experiments.

current declined almost completely $(P<0.001$, Fig. 3B). The HmK toxin affected the current of Kv3.4 channels not only dose dependently but also in a voltage dependent manner (Fig. 4). While the current firstly inhibited by $10 \mu \mathrm{M}$ concentration of HmK $(P<0.01)$, during the voltage clamping, at the membrane potentials more than $10 \mathrm{mV}$ the current increased slowly with a lesser slope.

However, bath application of different concentrations of DTx including, $\alpha$-dendrotoxin, DPI, DPK and also, $\beta$-bungarotoxin and corotoxin (even up to $100 \mathrm{mM}$ ) could not induce any change in current amplitude.

\section{DISCUSSION}

In comparison to the whole oocyte cells which are less sensitive to be blocked by certain pharmacological agents and inactivate more slowly, cloned $\mathrm{Kv}$ channels stably expressed in mammalian cell lines are likely to have biophysical properties more closely resembling those of native channels. Also, a large number of transfected cells can be generated by standard cell culture technique, which could facilitate their use in high-throughput drug or toxinscreening assays [2].

Previous investigations have shown that TEA and also 4-aminopyridine can block potassium channel 
types Kv1.1, Kv1.2, Kv1.3, Kv1.5 and Kv3.1 [12]. Our study demonstrates the blocking effect of TEA and 3, 4-DAP on Kv3.4 channels. It shows that $\mathrm{Kv} 3.4$ channels are more sensitive to 3, 4-DAP in comparison to Kv1.1 and Kv3.1 channels. However, new studies have shown that sea anemone peptides such as BDS I and II are the first specific blockers identified for the rapidly inactivating Kv3.4 channels, but these peptides also affect weakly $\mathrm{Na}^{+}$ channels [5]. These toxins which include 43 amino acids, differ only at two position and share no sequence homologies with other $\mathrm{K}^{+}$channel toxins from sea anemones, such as AsKs, AsKc, ShK , $\mathrm{BgK}$ or HmK that are effective on Kv1.2 and Kv1.3 $[3,5]$.

In this study, Bgk also inhibited the Kv3.4 channels current at $\mu \mathrm{M}$ concentrations. In comparison to BDS I and II, the $\mathrm{BgK}$ toxin is weaker and the former toxins can block the current rapidly at $\mathrm{nM}$ concentrations [16]. While, these toxins have no sequence homologies (with the exception of three disulfide bridges), their secondary structure and biological activity are very important to constitute molecular probes useful for investigation of $\mathrm{K}+$ channel properties. Although, toxins including, TEA, DAP, BgK, HmK (used in this study) and BDS are very different in their chemical structures and have not any homology with each other, they are effective blockers of Kv3.4 channels.

The functional properties of molecules and especially proteins are frequently associated with a small number of important residues in the structure [11]. It had been shown that although, BgK and ChTx have different structures, they both inhibit the binding of labeled DTx to potassium channels, suggesting that they bind to regions of the channel that are recognized by DTx. The recognition sites for these toxins commonly include the very conserved p-region of the pore of the channels [16]. Therefore, toxins that have unrelated structures but similar functions may possess conserved key functional residues, organized in an identical topology, suggesting a convergent functional evolution for these small proteins or structures [3]. Although, new findings have suggested that the residue at a specific position of a channel may control the affinity of a number of blocking toxins [17].

Although, HmK and DAP seem to shift the threshold potential towards more positive voltages, inhibit the currents more potently at lower potentials and reduce the slope for I-V curves, this is more prominent for HmK toxin.
The kinetic of the activity of $\mathrm{HmK}$ on $\mathrm{Kv} 3.4$ channels is probably different from other toxins, and the outward current activated at more positive potentials, suggesting that during the increment of the membrane potential (eg. more than $10 \mathrm{mV}$ ) the toxin could be dissociated from the subunit of a number of channels. The significance of these channels characterized by positively shifted voltage dependencies and very fast deactivation rates, is very important for development of rapid neuronal depolarization. These properties are adaptations that allow these channels to produce currents that can specifically enable fast repolarization of action potentials without compromising spike initiation or height. Activation of these channels can accelerate the recovery of channels to the rest after the action potential $[6,8]$. Several neuronal systems in the mammalian CNS have incorporated into their repertoire a relatively large number of Kv3 channels to enable repetitive firing at high frequencies $[4,6$, 10]. The functional consequence of fast inactivation produced by Kv3.4 subunits still remain to be studied. The recent finding has showed that Kv3.4 subunits associate with MiRP2 proteins in skeletal muscle to form subthreshold-operating channels that contribute to setting of the resting potential of muscle cell [6]. Localization of Shaw Kv3.4 channel to astrocytic processes suggests that these channels may enable astrocytes to respond rapidly to high frequency synaptic events or incoming signals, possibly synchronizing astrocyte function to neuronal activity [4].

Regarding to the concentrations and the blocking activity of toxins used in this study and previous findings, we could not find more selective molecule on Kv3.4 channels. In addition, DAP derivatives (especially 4-aminopyridine) are not selective blockers and affect most $\mathrm{K}+$ channels at $\mathrm{mM}$ concentrations [12], but in respect to their blocking activity on Kv3.4 channels at $\mu \mathrm{M}$ concentrations, they could be useful to find relationship between basic molecular structures and their inhibitory activity to design new more selective and effective compounds on these channels.

\section{REFERENCES}

1. Lavrestsky, E.P. and Jarrik, L.F. (1992) A Group of potassium-channel blockers-acetylcholine releasers: New potential for Alzheimer disease? A Review. $J$. Clin. Psychopharmacol. 12: 110-118.

2. Grissmer, S., Nguyen, A., Aiyar, J., Hanson, D.C., Mather, R.J., Gutman, J.A., Karmilowicz, M.J., 
Auperin, D.D. and Chandy, K.G. (1994) Pharmacological characterization of five cloned voltage-gated $\mathrm{K}+$ channels, types Kv1.1, 1.2, 1.3, 1.5 and 3.1, stably expressed in mammalian cell lines. Mol. Pharmacol. 45: 1227-1239.

3. Dauplais, M., Lecoq, A., Song, J., Cotton, J., Jamin, N., Gilquin, B., Roumestand, C., Vita, C., Medeiros, C.L., Rowan, E.G., Harvey, A.L. and Menz, A. (1997) On the convergent evolution of animal toxins. J. Biol. Chem. 272: 4302-4309.

4. Bekar, L.K., Loewen, M.E., Cao, K., Sun, X., Leis, J., Wang, R., Forsyth, G.W. and Walz, W. (2005) Complex expression and localization of inactivating $\mathrm{Kv}$ channels in cultured hippocampal astrocytes. $J$. Neurophysiol. 93: 1699-1709.

5. Diochot, S., Schweitz, H., Beress, L. and Lazdunski, M. (1998) Sea Anemone peptides with a specific blocking activity against the fast inactivating potassium channel Kv3.4. J. Biol. Chem. 273: 67446749.

6. Rudy, B. and McBain, C.J. (2001) Kv3.4 channel: Voltage-gated $\mathrm{K}^{+}$channels designed for highfrequency repetitive firing. Trends Neurosci. 24: S17-S26.

7. Harvey, A.L., Anderson, A.J., Marshall, D.L., Rowan, E.G., Vatanpour, O.C. and Karlsson, E. (1992) Neurotoxins acting on ion channels and modulating transmitter release. Neuroceptor, Ion channels and the Brain. 42: 35-41.

8. Riazanski, V. (2001) Functional and molecullar analysis of transient voltage-dependent $\mathrm{K}+$ currents in rat hippocampal granule cells. J. Physiol. 532: 391-406.

9. McKay, B.E. and Turner, R.W. (2004) Kv3 K channels enable burst in rat cerebellar purkinje cells. Eur. J. Neurosci. 20: 729-739.

10. Armstrong, C.M. and Hill, B. (1998) Voltage-gated ion channels and electrical excitability. Neuro 20: 371-380.
11. Harvey, A.L., Rowan, E.G., Vatanpour, H., Young, L.C., Castaneda, O., Mebs, D., Cervenansky, C. and Karlsson, E. (1996) Potassium channel neurotoxins from sea anemones. In: Biochemical Aspects of Marine Pharmacology, (Lazarovici, P., Spira, M.E. and Zlotkin, E. eds.), Vol. 1, Alaken, Fort Collins, pp. 121-131.

12. Pongs, O. (1992) Molecular biology of voltagedependent potassium channels. Physiol. Rev. 72: S69-S88.

13. Shelton, P.A. and Dart, C. (1996) The use of the rat LAPLCR and promoter for high-level constitutive expression of $\mathrm{K}+$ channel cDNAs in a rat liver cell line. FEBS Let. 39: 262-286.

14. Hamil, O.P., Marty, A., Neher, E., Sakmann, B. and Sigworth, F.J. (1981) Improved patch-clamp techniques for the high resolution current recording from cells and cell-free membrane patches. Pflugers Arch. 391: 85-100.

15. Dempster, J.L. (1988) Computer analysis of electrophysiological signals. In: Microcomputer in Physiology: A practical approach. (Frazer P.J. ed.), IRL Press, Oxford. pp. 51-93.

16. Cotton, J., Crest, M., Bouet, F., Alessandri, N., Gola, M., Forest, E., Karlsson, E., Cast-aneda, O., Harvey, A.L., Vita, C. and Menzo, A. (1997) A potassium channel toxin from the sea anemone Bunodosoma granulifera, an inhibitor for Kv1 channels. Revision of the aminoacid sequence, disulfide-bridge assignment, chemical synthesis, and biological activity. Eur. J. Biochem. 244: 192-202.

17. Gilquin, B., Braud, S., Eriksson, M.A.L., Roux, B., Bailey, T.D., Priest, B.T., Garcia, M.L., Menez, A. and Gasparini, S. (2005) A variable residue in the pore of $\mathrm{Kv1}$ channels is critical for the high affinity of blockers from sea anemones and scorpions. $J$. Biol. Chem. 280: 27093-27102. 